NBER WORKING PAPER SERIES

\title{
DEATHS RISE IN GOOD ECONOMIC TIMES: EVIDENCE FROM THE OECD
}

\author{
Ulf-G. Gerdtham \\ Christopher J. Ruhm \\ Working Paper 9357 \\ http://www.nber.org/papers/w9357 \\ NATIONAL BUREAU OF ECONOMIC RESEARCH \\ 1050 Massachusetts Avenue \\ Cambridge, MA 02138 \\ November 2002
}

Financial support from the Swedish National Institute of Public Health to Gerdtham and the National Science Foundation (SES9876511) to Ruhm is gratefully acknowledged. The opinions, findings, conclusions, or recommendations expressed are those of the authors and do not necessarily reflect the views of the funding agencies. The views expressed herein are those of the authors and not necessarily those of the National Bureau of Economic Research.

(C) 2002 by Ulf-G. Gerdtham and Christopher J. Ruhm. All rights reserved. Short sections of text, not to exceed two paragraphs, may be quoted without explicit permission provided that full credit, including (C) notice, is given to the source. 
Deaths Rise in Good Economic Times: Evidence From the OECD

Ulf-G. Gerdtham and Christopher J. Ruhm

NBER Working Paper No. 9357

November 2002

JEL No. E32, J2, I12

\section{ABSTRACT}

This study uses aggregate data for 23 OECD countries over the 1960-1997 period to examine the relationship between macroeconomic conditions and fatalities. The main finding is that total mortality and deaths from several common causes increase when labor markets strengthen. For instance, controlling for year effects, location fixed effects, country-specific time trends and demographic characteristics, a one percentage point decrease in the national unemployment rate is associated with a 0.4 percent rise in total mortality and $0.4,1.1,1.8,2.1$ and 0.8 percent increases in deaths from cardiovascular disease, influenza/pneumonia, liver disease, motor vehicle fatalities and other accidents. These results are consistent with the findings of other recent research and cast doubt on the hypothesis that economic downturns have negative effects on physical health.

Ulf-G. Gerdtham

Department of Community Medicine and

Lund University Centre for Health Economics

Lund University

Box 705, SE-220 07

Lund, Sweden

ulf.gerdtham@luche.lu.se
Christopher J. Ruhm

Department of Economics

University of North Carolina at Greensboro P.O. Box 26165

Greesnboro, NC 27402-6165

and NBER

c_ruhm@uncg.edu 


\section{Deaths Rise in Good Economic Times: Evidence from the OECD}

\section{$\underline{1 . \text { Introduction }}$}

Widely cited analyses of aggregate time-series data by Harvey Brenner (1973, 1975, 1979) reveal a countercyclical variation in admissions to mental hospitals, infant mortality rates, and deaths due to cardiovascular disease, cirrhosis, suicide, and homicide. However, this research suffers from serious technical flaws (Gravelle, et al., 1981; Stern, 1983; Wagstaff, 1985; Cook \& Zarkin, 1986) and studies correcting the problems (Forbes \& McGregor, 1984; McAvinchey, 1988; Joyce \& Mocan, 1993) fail to uncover a consistent relationship between the macroeconomy and health. ${ }^{1}$ Instead, the results are sensitive to the choice of countries, time periods, and outcomes, with falling unemployment frequently being correlated with worse rather than better health. This lack of robustness is not surprising since any lengthy time-series may contain confounding factors that are spuriously correlated with economic conditions. ${ }^{2}$

Ruhm (2000) has recently addressed the omitted variables bias issue by estimating fixedeffect (FE) models for a panel of the 50 states and District of Columbia over a 20 -year period (1972-1991). These specifications exploit within-state changes and so automatically control for time-invariant factors that are spuriously correlated with economic conditions across locations. Strong evidence is provided that mortality increases when labor markets are tight.

Unemployment is negatively and significantly related to total mortality and 8 of 10 specific causes of fatalities, with suicides the important exception. For instance, a one percentage point

\footnotetext{
${ }^{1}$ Criticisms of Brenner's research include his method of choosing lag lengths, the hypothesized pattern of lag coefficients, choice of covariates, and the plausibility of his results.

${ }^{2}$ For example, much of the variation in unemployment occurring during the four decades (beginning in the 1930s) covered by Brenner's research resulted from dramatic reductions in joblessness following the great depression. During this same period, health improved due to better nutrition and increased availability of antibiotics. Failure to control for these factors leads to an overstatement of the detrimental health impact of unemployment.
} 
fall in the state unemployment rate is associated with $0.5,3.0,0.7$, and 0.4 percent increases in deaths from all causes, motor vehicle fatalities, flu/pneumonia, and heart disease.

This analysis examines whether the finding that death rates increase when labor markets strengthen is generalizable across industrialized countries that often have quite different economic institutions, lifestyles, and systems of medical care. Specifically, we examine whether fatalities rise when labor market conditions improve using information for 23 member nations of the Organization for Economic Cooperation and Development (OECD) over the 1960-1997 period. Countries are the unit of observation and we investigate how total mortality and nine specific causes of deaths vary with national unemployment rates (or the percentage of the population employed), after controlling for time-invariant country-specific factors, general time effects, demographic characteristics and (usually) country-specific time trends.

Our major finding is that robust economic conditions are associated with increases in total mortality rates and several important sources of death. In our preferred model, a one percentage point decrease in the national unemployment rate is estimated to raise total mortality by 0.4 percent and deaths from cardiovascular disease, influenza/pneumonia, liver disease, motor vehicle fatalities and other accidents by $0.4,1.1,1.8,2.1$ and 0.8 percent. Conversely, deaths from cancer are largely unaffected and there is some evidence that suicides and homicides decline in good economic times.

These results lend support to the hypothesis that physical health deteriorates when labor market conditions improve and generally accord with the findings of recent research using similar methods and data (e.g. Ruhm, 2000; Tapia Granados, 2002; Neumayer, 2002). However, the mechanisms for these effects may be complicated and varied across sources of death. For instance, higher incomes are predicted to reduce some but raise other types of fatalities, and the 
dynamics of the adjustment to a sustained change in unemployment differs with the cause of mortality.

\section{Why Might Deaths Increase in Good Economic Times?}

Many researchers hypothesize that cyclical upturns benefit health by reducing the stress associated with economic insecurity (e.g. Brenner and Mooney, 1983; Catalano and Dooley, 1983; Fenwick and Tausig, 1994). However, there are at least three reasons why health might instead worsen. First, non-market "leisure" time decreases, making it more costly for individuals to undertake time-intensive health-producing activities such as exercise. Consistent with this, analysis of data from the Behavioral Risk Factor Surveillance System (BRFSS) suggests that lower joblessness is associated with increased smoking and obesity, reduced physical activity, and worse diet (Ruhm, 2000, 2002a). ${ }^{3}$

Second, health may be an input into the production of goods and services. Most obviously, hazardous working conditions, the physical exertion of employment, and job-related stress could have negative effects, particularly when job hours are extended during short-lasting economic expansions (Baker, 1985; Karasek and Theorell, 1990; Sokejima and Kagamimori, 1998). Cyclically sensitive sectors, such as construction, also have high accident rates and some joint products of economic activity (like pollution or traffic congestion) present health risks. ${ }^{4}$

\footnotetext{
${ }^{3}$ The time price of medical care may also decline if persons working fewer hours find it easier to schedule medical appointments for themselves or their dependents. Consistent with this, Mwabu (1988) and Vistnes and Hamilton (1995) report a negative relationship between employment and the utilization of medical care.

${ }^{4}$ For instance, Chay and Greenstone (1999) show that county-level reductions in pollution associated with the 19811982 recession led to substantial decreases in infant mortality. Small negative health shocks associated with transitory upturns might also cause frail individuals to die slightly sooner than they otherwise would, even while having little impact on overall life expectancy. This phenomenon is referred to as "harvesting" by epidemiologists. There is also a large literature documenting a procyclical pattern in workplace absenteeism (e.g. Leigh, 1985; Kaivanto, 1997; Arai and Thoursie, 2001). This is generally believed to result from negative selection into employment during good times (i.e. sicker individuals can more easily find jobs when the economy is robust) or increased shirking due to reduced fear of job loss (Calvo, 1979; Salop, 1979; Shapiro and Stiglitz, 1984). However, this pattern is also consistent with worsening health when labor markets strengthen.
} 
Third, income growth may increase some risky activities (such as driving or skiing), raising deaths from external causes like vehicle fatalities (Evans and Graham, 1988; Ruhm, 1995; Freeman, 1999) and possibly elevating related non-fatal accidents and health problems.

We use standardized unemployment rates as our main proxy of labor market conditions. However, it is important to realize that reductions in mortality during bad times need not be restricted to or even concentrated among those becoming newly unemployed. To the contrary, job loss could induce stress that counteracts other beneficial effects and thus raise death rates among jobless individuals, even while overall mortality declines. ${ }^{5}$ There is also no reason to believe that all types of health respond in the same way. For instance, increasing stress provides one reason why mental health might deteriorate despite gains in physical well-being. ${ }^{6}$ Similarly, we expect to see larger fluctuations in fatalities from sources such as cardiovascular disease that may be strongly and rapidly affected by changes in lifestyles, environmental factors, and medical interventions, then for those like cancer that probably are not.

It should be emphasized that increased mortality associated with transitory strengthening of the labor market does not imply negative effects of permanent economic growth. The key distinction is that agents have greater flexibility in making consumption, production, and timeallocation decisions in the long-run. Thus, temporary increases in output usually involve more intensive use of labor and health inputs with existing technologies, whereas permanent growth results from improvements in technology or expansions in the capital stock that push out the

\footnotetext{
${ }^{5}$ There is no doubt that the nonemployed are in worse average health than workers (e.g. Morris, et al., 1994; Currie and Madrian, 1999; Ettner, 2000; Gerdtham and Johannesson 2002a). However, since poor health probably reduces employment probabilities, the direction of causation is poorly understood (Bartley, 1996; Goldney, 1997; Smith 1999). Martikainen and Valkonen (1996) examine this by comparing mortality of persons losing jobs in Finland during times of relatively low and high joblessness. Consistent with the hypothesis of stronger selection during good times, they find that the association between unemployment and subsequent mortality weakens as joblessness rises. ${ }^{6}$ Jobless persons are more likely to be mentally ill or commit suicide than employed individuals (Dooley, et al., 1988; Catalano, 1991; Lewis and Slogget, 1998; Mortensen, et al., 2000). While it is difficult to infer causation
} 
production possibility frontier and so have the potential to ameliorate or eliminate costs to health.

Similarly, individuals may be more likely to defer health investments in response to temporary

than permanent increases in work hours, while sustained income growth permits purchases of consumption goods (such as vehicle safety) that improve health. ${ }^{7}$

\section{Estimation strategy}

We use linear regression to estimate the relationship between labor market conditions and fatality rates. Using the subscripts $\mathrm{j}$ and t to index the country and year, the basic specification is:

$$
M_{j t}=\alpha_{t}+X_{j t} \beta+E_{j t} \gamma+C_{j}+\varepsilon_{j t}
$$

where $\mathrm{M}$ is the natural $\log$ of the mortality rate, $\mathrm{E}$ is the unemployment rate, $\mathrm{X}$ is a vector of regressors controlling for the age and sex distribution of population, $\alpha$ is year-specific intercept, $\mathrm{E}$ is a country fixed-effect, and $\varepsilon$ is a disturbance term.

The year effect holds constant determinants of health that vary uniformly across countries over time (e.g. the effects of oil shocks). The fixed-effect accounts for factors that differ across locations but are time-invariant (such as some country-specific institutions). Therefore, the impact of the macroeconomy is identified by within-country variations in unemployment rates, relative to the changes occurring in other nations. ${ }^{8}$ Importantly, these estimates automatically control for cross-country differences in the determinants of health (such as lifestyles and

\footnotetext{
from these studies, a careful investigation by Hamilton, Merrigan, and Dufresne (1997) finds a detrimental effect even after accounting for the endogeneity between mental illness and unemployment.

${ }^{7}$ Ettner (1996), Pritchett and Summers (1996), and Gerdtham and Johannesson (2002b,c) provide examples of research showing a positive relationship between income and health. Graham, Chang, and Evan's [1992] analysis of U.S. data indicates that mortality rates are negatively (positively) related to permanent (transitory) income as proxied by per capita consumption (the inverse of unemployment). Conversely, Snyder and Evans (2002) show that reduced incomes of the Social Security "notch" beneficiaries were associated with decreased mortality.

${ }^{8}$ For the fixed-effect estimates to be useful, there must be substantial independent fluctuations in labor market conditions across countries over time. This condition appears to be met. The squared-correlation coefficient between national and OECD unemployment rates is less than 0.5 for 12 of the 23 countries and below 0.25 for six. The R-squared from regressing national unemployment rates on the OECD-wide rate is just 0.33.
} 
geographic factors) that remain constant over time, as well as determinants (like medical technologies) that vary over time but are rapidly diffused across countries.

Most models also include a vector of country-specific linear time trends $\left(\mathrm{C}_{\mathrm{j}}^{*} \mathrm{~T}\right)$, to control for factors that vary over time within nations (for example, the level of education), implying the regression equation:

$$
M_{j t}=\alpha_{t}+X_{j t} \beta+E_{j t} \gamma+C_{j}+C_{j} * T+\varepsilon_{j t}
$$

We also experiment with models that incorporate controls for the OECD-wide unemployment rate, and some specifications hold per capita incomes constant, to examine whether the macroeconomic fluctuations in mortality partially reflect changes in incomes.

The regressions are usually estimated by weighted least squares (with observations weighted by the square root of the national population) to account for heteroscedasticity. We also test whether the results are sensitive to using unweighted data or allowing for first-order autocorrelation, with country-specific AR(1) coefficients.

\section{Data}

Annual information on fatality rates, country characteristics, and per capita disposable income are obtained for 23 OECD countries over the 1960-1997 period from the OECD Health Data 2000 (OECD, 2000). ${ }^{9}$ The outcomes examined are the total mortality rate and deaths from nine leading causes: malignant neoplasms (cancer), major cardiovascular (heart) disease, influenza/pneumonia, liver disease and cirrhosis, motor vehicle accidents, other accidents, suicides, homicides, and infant deaths. ${ }^{10}$

\footnotetext{
${ }^{9}$ See www.oecd.org/health for details and documentation.

${ }^{10}$ The nine causes account for approximately 80 percent of all deaths.
} 
Standardized unemployment rates are our primary proxy of labor market conditions, with information supplied from two sources. Rates for 10 countries (Australia, Canada, France, Germany, Italy, Japan, Netherlands, Sweden, United Kingdom, and the United States) come from a consistent series developed by the U.S. Bureau of Labor Statistics, with data available starting in the first year of our analysis for all nations except the Netherlands, where the series begins in $1973 .{ }^{11}$ Standardized rates for 13 additional countries (Austria, Belgium, The Czech Republic, Denmark, Finland, Ireland, Luxembourg, New Zealand, Norway, Poland, Portugal, Spain, and Switzerland) are obtained from several issues of the OECD Employment Outlook and start in various years. ${ }^{12}$

The regressions also control for the percentage of the population that is male and in three age ranges $(15-64,65-74$, and $\geq 75)$, since these characteristics may independently affect death rates. Country fixed-effects, general time effects, and (usually) country-specific time trends are also included. Finally, some models control for net national disposable income per capita, in thousands of 1990 dollars measured at purchasing power parities and converted to constant dollars using the US GDP price deflator. ${ }^{13}$

Table 1 provides summary statistics. The panel contains 525 country-year observations, or an average of 23 observations per country (ranging from 4 to 38). Missing data reduce sample sizes slightly for cancer and heart disease and considerably more homicides and non-vehicle accidents. Deaths from most sources have trended downwards. For instance, the total mortality rate fell by 8 percent (from 944 to 873 deaths per 100,000 population) between 1960 and 1995,

\footnotetext{
${ }^{11}$ The data were obtained from: www.bls.gov/fls/flslforc.pdf. Information for Germany refers to West Germany, with analysis limited to the 1960-1990 (prior to unification), to avoid problems of comparability.

${ }^{12}$ Starting years are 1973 for Norway and Spain, 1980 for Belgium and Finland, 1982 for Denmark, Ireland, Luxembourg, and New Zealand, 1983 for Portugal, 1991 for Switzerland, 1992 for Hungry, and 1993 for the Czech Republic and Poland.

${ }^{13}$ We use purchasing power parities instead of conventional market exchange rates because the latter overstate (understate) real income in high (low) income countries (Kravis, et al. 1978).
} 
fatality rates from cardiovascular disease and vehicle accidents declined 22 and 27 percent respectively, and infant mortality decreased 78 percent. ${ }^{14}$ Conversely, death rates from cancer increased 43 percent, largely reflecting aging of the population.

To provide a first indication of the relationship between deaths and macroeconomic conditions, Figure 1 displays (population-weighted) OECD total mortality and unemployment rates from 1960 to 1995 where, for ease of interpretation, these variables have been detrended and normalized to have a mean of zero and a standard deviation of one. ${ }^{15}$ Previewing the econometric results to follow, the figure suggests a fairly strong inverse relationship between labor market conditions and fatality rates. ${ }^{16}$ Although the OECD-wide may suffer from the aforementioned problems of confounding, implying the need for a careful multivariate analysis, these findings suggest that the possibility that deaths increase in good economic times.

\section{Mortality Rises in Good Times}

Table 2 summarizes the results of a variety of econometric models, all showing that deaths rise when labor markets are strong. Here and below, the tables display the estimated effect of a one percentage point increase in the standardized unemployment rate. Specification (a) shows the results of regressing the natural log of the total fatality rate on unemployment, country demographic characteristics (sex and age), fixed-effects, year-effects, and countryspecific linear time trends. The statistically significant coefficient of -.0040 indicates that a one

\footnotetext{
${ }^{14}$ To avoid changes in sample composition, these calculations are performed using information for the eight countries (Australia, Canada, France, Italy, Japan, Sweden, United Kingdom, and the United States) on which mortality and unemployment data are available throughout the 35 year period. Similar trends are obtained using an unbalanced panel of nations with information available in the two end years.

${ }^{15}$ Unemployment trends upwards an average of 0.14 percentage points per year and total mortality downwards by 3.0 deaths per 100,000 persons annually. This analysis is restricted to the same eight countries as in the previous paragraph, although substantially similar findings are again obtained using an unbalanced panel of nations.

${ }^{16}$ Regressing the natural log of total mortality on unemployment rates (using the detrended data) yields an unemployment coefficient of -0.409 with a standard error of 0.159 .
} 
percentage point fall in joblessness is estimated to raise mortality by 0.4 percent. $^{17}$ Since joblessness averages 5.6 percent, a one point decrease corresponds to a drop of approximately 18 percent and the unemployment elasticity of total mortality is around $-.022 .^{18}$

Column (b) adds controls for per capita incomes. There is no indication that mortality grows during strong labor markets because incomes increase. Instead, the latter appear to have a protective effect: a rise of $\$ 1000$ (roughly 7 percent) reduces the estimated death rate by around 15 percent, corresponding to an income elasticity of $-0.17 .{ }^{19}$ Moreover, the effect of unemployment would be 68 percent greater than in column (a), were it not for the offsetting benefits of higher incomes. However, we show below that the estimated income elasticities vary substantially across causes of death.

The next four columns test the robustness of the results to a variety of alternative specifications. Country-specific time trends are omitted in model (c) and year effects are excluded in specification (d). Column (e) substitutes the (population-weighted) mean OECD unemployment rate for the national rates. Finally, specification (f) includes both the OECD and national unemployment rates. Deaths are predicted to increase when labor markets tighten in all of these models. The unemployment coefficient shrinks somewhat when country-specific trends are excluded (model c) and increases in the absence of general time effects (column d). The estimated effects are almost identical when OECD rather than country unemployment rates are controlled for (specification e) but national conditions dominate when including both (model f).

\footnotetext{
${ }^{17}$ Similarly, a one standard deviation (3.62 percent) decline in unemployment is associated with a 1.5 rise in total mortality.

${ }^{18}$ Deaths are also predicted to increase with the population share of persons aged $65-74$ or 75 and above, and to decline with the fraction of persons younger than 15. The percent male has little effect on total mortality.

${ }^{19}$ Lutter and Morall III (1994) estimate an income elasticity of - 0.32 using World Bank data for 101 countries over the years 1965-1985. The higher elasticity they obtain is partially due to differences in model specification (e.g. they do not control for unemployment rates or country-specific trends) and is likely to partly reflect their inclusion of developing countries, where the protective effect of income on health is more pronounced.
} 
We also estimated models using unweighted data or allowing for autocorrelation of the error term with country-specific AR(1) processes. These results (not shown) again indicate a negative correlation between unemployment rates and total mortality, that occurs despite rather than because of the associated changes in incomes. We included a quadratic of the unemployment rate, to test for a nonlinear relationship, but found no evidence of one. Specifications that controlled for the percentage of the 20-64 year olds employed (rather than the unemployment rate) again predict increased mortality when labor markets strengthen. ${ }^{20}$

Table 3 summarizes the results obtained using alternative specifications of the dependent variable or subsamples of the data. The first two columns repeat the basic estimates presented in models (a) and (b) of Table 2. The third and fourth columns use deaths in levels (rather than natural $\operatorname{logs}$ ) as the outcome and again indicate elevated mortality during strong labor markets, that occurs despite a protective effect of income. A one point decline in unemployment is associated with a 2.94 per 100,000 population increase in deaths (see model c), corresponding to a 0.3 percent growth at the dependent variable mean. An extra $\$ 1000$ of income is estimated to reduce fatalities by 102.6 per 100,000, or 11.3 percent (model d). The fifth and sixth columns restrict the analysis to the 10 countries with the largest population (in 1990), since measurement error problems may be least severe for them. ${ }^{21}$ Doing so somewhat increases the size of the macroeconomic effect - a one point fall in joblessness is estimated to increase the total death rate by 0.5 percent. The last two columns limit analysis to the 1983-1997 period, where standardized unemployment rates are available for almost all countries. The increase in mortality estimated to

\footnotetext{
${ }^{20}$ Employment-to-population ratios were used because some economists (e.g. Clark and Summers, 1982) argue that they provide a more accurate measure of labor market conditions for groups frequently entering and exiting the labor force. The income coefficient in these models is again negative but not statistically significant and only about 30 percent as large as when unemployment was controlled for.

${ }^{21}$ These include the United States, Japan, Germany, United Kingdom, Italy, France, Spain, Canada, Australia, and the Netherlands.
} 
accompany a drop in unemployment rises considerably when this is done: the one point fall in joblessness correlates with a 0.6 percent rise in fatalities. One reason for this is the much weaker estimated (protective) income effect.

\section{Cause-Specific Mortality}

Table 4 demonstrates that deaths from a variety of causes increase when labor markets strengthen. The econometric models again control for location fixed effects, country-specific time trends, general year effects, national demographic characteristics, and (in specification b) per capita incomes. A one point fall in the standardized unemployment rate is estimated to raise fatalities from cardiovascular disease, flu/pneumonia, or liver disease by a statistically significant $0.4,1.1$, and 1.8 percent, with small (and insignificant) growth also predicted for infant deaths. These results accord with those found for the United States by Ruhm (2000).

It makes sense that macroeconomic conditions are unrelated to cancer mortality, since deaths from this source may be less affected by short-lasting changes in medical care or lifestyles. The strong procyclical variation in accidental fatalities - a one point decline in joblessness is predicted to raise vehicle deaths by 2.1 percent and mortality from other accidental causes by .08 percent - is also consistent with the results of earlier research and seems reasonable, since risky activities such as driving increase in good economic times. Conversely, suicides are estimated to fall by a statistically insignificant 0.4 percent and homicides by a significant 1.1 percent. $^{22}$

The income effects are mixed (see model b). Consistent with the results for total mortality, higher incomes are correlated with significantly lower infant death rates and fatalities from cancer and flu/pneumonia. The coefficients for homicides and non-vehicle accidents are

\footnotetext{
${ }^{22}$ Ruhm (2000) also finds that suicides are countercyclical but, unlike this analysis, demonstrates that homicides rise in good economic times in the United States.
} 
also negative and large but imprecisely estimated. Conversely, rising incomes are linked to increased deaths from heart disease and a statistically insignificant rise in mortality from vehicle accidents and liver ailments. These diverse effects suggest a complicated role for income that deserves further study. ${ }^{23}$

\section{Dynamics}

Economic conditions have been assumed to have only a contemporaneous impact on mortality until now. Information on the dynamics of the adjustment process was obtained by estimating models that include 4-year lags of the national unemployment rate and calculating the impact of a one percentage point rise in joblessness persisting for k years as $\sum_{n=0}^{k} \hat{\beta}_{t-n}$, for $\hat{\beta}_{t-n}$ the regression coefficient on the n-year lag of unemployment.

The adjustment patterns vary substantially across causes of death. ${ }^{24}$ For instance, falling unemployment is predicted to lead to rapid and sustained increases in the total fatality rate: a lasting one percent decline in joblessness is estimated to raise overall mortality by $0.5,0.4$, and 0.6 percent after 0,2 , and 4 years (with standard errors of 0.2 percent in each case). This reflects fatalities from sources such as flu/pneumonia or liver disease that rise over time. By contrast, the 1.4 percent initial increase in deaths predicted from cardiovascular disease weakens to 0.2 percent after two years and completely disappears by the end of four. Similarly, traffic fatalities are estimated to grow 2.5 percent in the year joblessness rises but by a smaller 2.3 percent after two years and 1.4 percent after four.

\footnotetext{
${ }^{23}$ Models that control for the percentage of the population employed, rather than the unemployment rate, yield results that are almost always consistent with those reported in this section.

${ }^{24}$ A table showing these results is available upon request for three years following the date of publication.
} 


\section{Discussion}

We provide evidence that deaths increase when labor markets strengthen. In the preferred specification, a one percentage point fall in the national unemployment rate is estimated to raise total mortality by 0.4 percent and fatalities due to cardiovascular diseases, flu or pneumonia, liver ailments, and vehicle accidents by $0.4,1.1,1.8$, and 1.9 percent. These patterns are similar to, although generally somewhat weaker than, those obtained in Ruhm's (2000) study of the United States using comparable methods and data. The smaller magnitude of the fluctuations might reflect institutional differences, such as universal access to health care in most OECD countries and the strong welfare state in many Western European nations.

Other recent research also indicates that health deteriorates when the economy temporarily improves. Tapia Granados (2002) and Neumayer (2002) document procyclical variations in mortality using Spanish and German data, while Ruhm (2002b) shows that medical conditions in the United States (particularly acute morbidities) become more prevalent when labor markets tighten. An exception is Gerdtham and Johannesson's (2002d) evidence of a countercyclical fluctuation in mortality for males (but not females) in Sweden using some business cycle measures, which might result from the strong social insurance system in that country. The dynamics of the adjustment to a sustained change in economic conditions varies across sources of death, however, suggesting that a diverse array of mechanisms may be responsible for these effects. For instance, the increase in cardiovascular mortality appears to dissipate fairly quickly, as might occur if higher time prices lead to initial reductions in exercise but with individuals gradually making arrangements to restore physical activity to previous levels (such as joining a health club that is close to work). Conversely, the rise in deaths from 
liver disease is estimated to grow over time, possibly reflecting the cumulative impact of a sustained increase in alcohol use. ${ }^{25}$

The role of income is similarly complex. Higher incomes are estimated to have a protective effect on overall mortality but with substantial variation across causes of death. Thus, income growth is associated with increased fatalities from heart disease, the single most important source of death, but with declining infant mortality and reductions in fatalities due to cancer or influenza/pneumonia. ${ }^{26}$

The results may also be sensitive to the choice of macroeconomic proxies. We have focused on unemployment rates, which provide a direct indication of labor market conditions and have frequently been used in other research. However, different findings might be obtained when using income-based macroeconomic proxies (such as changes in GDP or deviations of GDP from trends). ${ }^{27}$ It would also be interesting to examine whether the results differ across population subgroups (such as males and females) that may be differentially affected by macroeconomic conditions. Finally, it would be useful to examine variations in other outcomes, such as sickness absenteeism, which causes welfare costs and production losses.

\footnotetext{
${ }^{25}$ See Ruhm (1995) or Ruhm and Black (2002) for evidence of a procyclical variation in drinking.

${ }^{26} \mathrm{Ruhm}$ (2000) generally obtains much weaker income effects for his analysis of the United States, raising further questions about the relationship between income and health.

${ }^{27}$ The notification rate (of plant closings and mass layoffs) might be a useful labor market indicator, since it is typically affected earlier in the business cycle than unemployment. Unfortunately, data on notification rates are not widely available. A rudimentary analysis suggested that the results obtained when regressing mortality rates on deviations of GDP from trend were sensitive to the specific choice of time periods and specifications.
} 


\section{References}

Arai, Mahmood and Peter S. Thoursie. 2001. "Incentives and Selection in Cyclical Absenteeism, mimeo, Stockholm University, January.

Baker, Dean B. 1985. "The Study of Stress at Work" Annual Review of Public Health, 6, 367-81.

Bartley, Mel. 1996. "Unemployment and Health Selection" The Lancet, 348, October 5, 904.

Brenner, M. Harvey. 1973. Mental Illness and the Economy. Cambridge: Harvard University Press.

Brenner, M. Harvey. 1975. "Trends in Alcohol Consumption and Associated Illnesses: Some Effects of Economic Changes" The American Journal of Public Health, 65(12), 1279-92. (1975b)

Brenner, M. Harvey. 1979. "Mortality and the National Economy" The Lancet, September 15, 568-73.

Brenner, M. Harvey and Anne Mooney. 1983. "Unemployment and Health in the Context of Economic Change” Social Science Medicine, 17(16), 1125-38.

Calvo Guillermo. 1979. "Quasi-Walrasian Theories of Unemployment” American Economic Review, 69(2), 102-107.

Catalano, Ralph. 1991. "The Health Effects of Economic Insecurity" American Journal of Public Health, 81(9), 1148-1152.

Catalano, Ralph and David Dooley. 1983. "Health Effects of Economic Instability: A Test of the Economic Stress Hypothesis" Journal of Health and Social Behavior, 24 (March), 46-60.

Chay, Kenneth Y. and Michael Greenstone. 2001. "The Impact of Air Pollution on Infant Mortality: Evidence from Geographic Variation in Pollution Shocks Induced By a Recession", mimeo, University of California at Berkeley.

Clark, Kim B. and Lawrence H. Summers. 1982. "The Dynamics of Youth Unemployment," in David A. Wise, ed., The Youth Labor Market Problem: Its Nature, Causes, and Consequences. Chicago: University of Chicago Press, 199-230.

Cook, Philip J. and Gary A. Zarkin. 1986. "Homicide and Economic Conditions: A Replication and Critique of M. Harvey Brenner's New Report to Congress" Journal of Quantitative Criminology, 2(1), 69-80.

Currie, Janet and Brigitte C. Madrian. 1999. "Health, Health Insurance and the Labor Market" in Orley C. Ashenfelter and David Card (eds.), Handbook of Labor Economics, Vol. 3c, Amsterdam: Elsevier Science B.V., 3309-3416. 
Dooley, David, Ralph Catalano, Karen Rook. 1988. "Personal and Aggregate Unemployment and Psychological Problems" Journal of Social Issues, 44(4), 107-23.

Ettner, Susan L. 1996. "New Evidence on the Relationship Between Income and Health" Journal of Health Economics, 15(1), 67-85.

Ettner, Susan L. 2000. "The Relationship Between Labor Market Outcomes and Physical and Mental Health: Exogenous Human Capital or Endogenous Health Production" in David S. Salkever and Alan Sorkin (eds.), Research in Human Capital and Development, Vol. 13: (The Economics of Disability), Stamford, CN: JAI Press, 1-31.

Evans, William and John D. Graham. 1988. "Traffic Safety and the Business Cycle" Alcohol, Drugs, and Driving, 4(1), 31-38.

Fenwick, Rudy and Mark Tausig. 1994. "The Macroeconomic Context of Job Stress" Journal of Health and Social Behavior, 35(3), 266-82.

Forbes, John F. and Alan McGregor. 1984. "Unemployment and Mortality in Post-War Scotland" Journal of Health Economics, 3, 219-57.

Freeman, Donald G. 1999. "A Note on 'Economic Conditions and Alcohol Problems"” Journal of Health Economics, 18(5), 661-670.

Gerdtham, Ulf-G. And Magnus Johannesson. 2002a. "A Note on the Effect of Unemployment on Mortality", mimeo, Lund University, September.

Gerdtham, U-G, Johannesson, M. 2002b. “Do Life-Saving Regulations Save Lives?” Journal of Risk and Uncertainty 24(3), 231-249.

Gerdtham, U-G, Johannesson, M. 2002c. "Absolute Income, Relative Income, Income Inequality and Mortality?" Journal of Human Resources, forthcoming.

Gerdtham, Ulf G. and Magnus Johannesson. 2002d. " Business Cycles and Mortality: Results From Swedish Micro Data”, mimeo, Lund University, November.

Goldney, Robert D. 1997. "Unemployment and Health: A Re-appraisal" International Archives of Occupational and Environmental Health, 70(3), 145-147.

Graham, John D., Bei-Hung Chang, and John S. Evans. 1992. "Poorer is Riskier," Risk Analysis, 12, 333-337.

Gravelle, H.S.E., G. Hutchinson, and J. Stern. 1981. "Mortality and Unemployment: A Critique of Brenner's Time Series Analysis" The Lancet, September 26, 675-9. 
Hall, R. (1988). The Relationship Between Price and Marginal Cost in US Industry. Journal of Political Economy, vol. 96, pp. 921-947.

Hamilton, Vivian H., Philip Merrigan, and Éric Dufresne. 1997. "Down and Out: Estimating the Relationship Between Mental Health and Unemployment" Health Economics, 6(4), 397406.

Joyce, Theodore and Naci Mocan. 1993. "Unemployment and Infant Health: Time-Series Evidence from the State of Tennessee" Journal of Human Resources, 28(1), 185-203.

Karasek, Robert A. and Töres Theorell. 1990. Healthy Work: Stress, Productivity, and the Reconstruction of Working Life. New York: Basic Books.

Kaivanto, Kim. 1997. “An Alternative Model of Pro-Cyclical Absenteeism”, Economics Letters, 54(1), January, 29-34.

Kravis, Irving B., Alan W. Heston, and Robert Summers. 1978. "Real GDP per capita for more than one hundred countries" Economic Journal 88(350), 215-242.

Leigh, J. Paul. 1985. "The Effects of Unemployment and the Business Cycle on Absenteeism", Journal of Economics and Business, 37(2), May, 159-170.

Lewis, Glyn and Andy Sloggert. 1998. "Suicide, Deprivation, and Unemployment: Record Linkage Study" British Medical Journal, 317, November 7, 1283-1286.

Lutter, Randall and John F. Morrall III. 1994. "Health-Health Analysis: A New Way to Evaluate Health and Safety Regulation" Journal of Risk and Uncertainty 8(1), 43-66.

Martikainen, Pekka T. and Tapani Valkonen. 1996. "Excess Mortality of Unemployed Men and Women During A Period of Rapidly Increasing Unemployment” The Lancet, 348, October 5,904 .

McAvinchey, Ian D. 1988. "A Comparison of Unemployment, Income, and Mortality Interaction for five European Countries" Applied Economics, 20, 453-471.

Morris, Joan K., Derek G. Cook, A. Gerald Shaper. 1994. "Loss of Employment and Mortality" British Medical Journal, 308, April 30, 1135-1139.

Mortensen, P.B., E. Agerbo, T. Erikson, P. Quin, and N. Westergaard-Nielsen. 2000. "Psychiatric Illness and Risk Factors for Suicide in Denmark" The Lancet, 355, January 1, 9-12.

Mwabu, Germano M. 1988. "Seasonality, The Shadow Price of Time and Effectiveness of Tropical Disease Control Programs" in Herrin, Alejando N. \& Patricia L. Rosenfield (eds.) Economics, Health, and Tropical Diseases, University of the Philippines Press, 259-270. 
Neumayer, Eric. 2002. "Recessions Lower (Some) Mortality Rates: Evidence From Germany”, mimeo, London School of Economics and Political Science, November.

OECD. 2000. OECD Health Data 2000: Comparative analysis of 29 countries. Version 07/15, Paris.

Pritchett, Lant and Lawrence H. Summers. 1996. "Healthier is Wealthier" The Journal of Human Resources, 31(4), 841-868.

Ruhm, Christopher J. 1995. "Economic Conditions and Alcohol Problems", Journal of Health Economics, 14(5), 583-603.

Ruhm, Christopher J. 2000. “Are Recessions Good for Your Health?” Quarterly Journal of Economics, 115(2), 617-650.

Ruhm, Christopher J. 2002. "Healthy Living in Hard Times", mimeo, University of North Carolina at Greensboro. (2002a)

Ruhm, Christopher J. 2002. "Economic Expansions Are Unhealthy”, mimeo, University of North Carolina at Greensboro. (2002b)

Ruhm, Christopher J. and William E. Black. 2002. "Does Drinking Really Decrease in Bad Times?" The Journal of Health Economics, 21(4), 659-678.

Salop Steven C. 1979. "A Model of the Natural Rate of Unemployment" American Economic Review, 69(1), 117-125.

Shapiro Carl and Joseph E. Stiglitz. 1984. "Equilibrium Unemployment as a Discipline Device" American Economic Review, 74(3), 433-444.

Smith, James P. 1999. "Healthy Bodies and Thick Wallets: The Dual Relation Between Health and Economic Status", Journal of Economic Perspectives, 13(2), 145-166.

Snyder, Stephen E. and William N. Evans. 2002. "The Impact of Income on Mortality: Evidence From the Social Security Notch", National Bureau of Economic Research Working Paper No. 9197, September.

Sokejima, Shigeru and Sadanobu Kagamimori. 1998 "Working Hours as a Risk Factor for Acute Myocardial Infarction in Japan: A Case-Control Study" The British Medical Journal, 317 (September 19), 775-780.

Stern, J. 1983. "The Relationship between Unemployment, Morbidity, and Mortality in Britain", Population Studies, 37, 61-74. 
Tapia Granados, José A.. 2002. "Death Rates and Business Cycle Fluctuations in Spain at the End of the $20^{\text {th }}$ Century: Further Empirical Evidence of the Mortality Increase During Economic Expansions", mimeo, New School University.

Vistnes, Jessica P. and Vivian Hamilton. 1995. "The Time and Monetary Costs of Outpatient Care for Children" American Economic Review, 85(2), 117-121.

Wagstaff, Adam. 1985. "Time Series Analysis of the Relationship Between Unemployment and Mortality: A Survey of Econometric Critiques and Replications of Brenner's Studies" Social Science Medicine, 21(9), 985-96. 


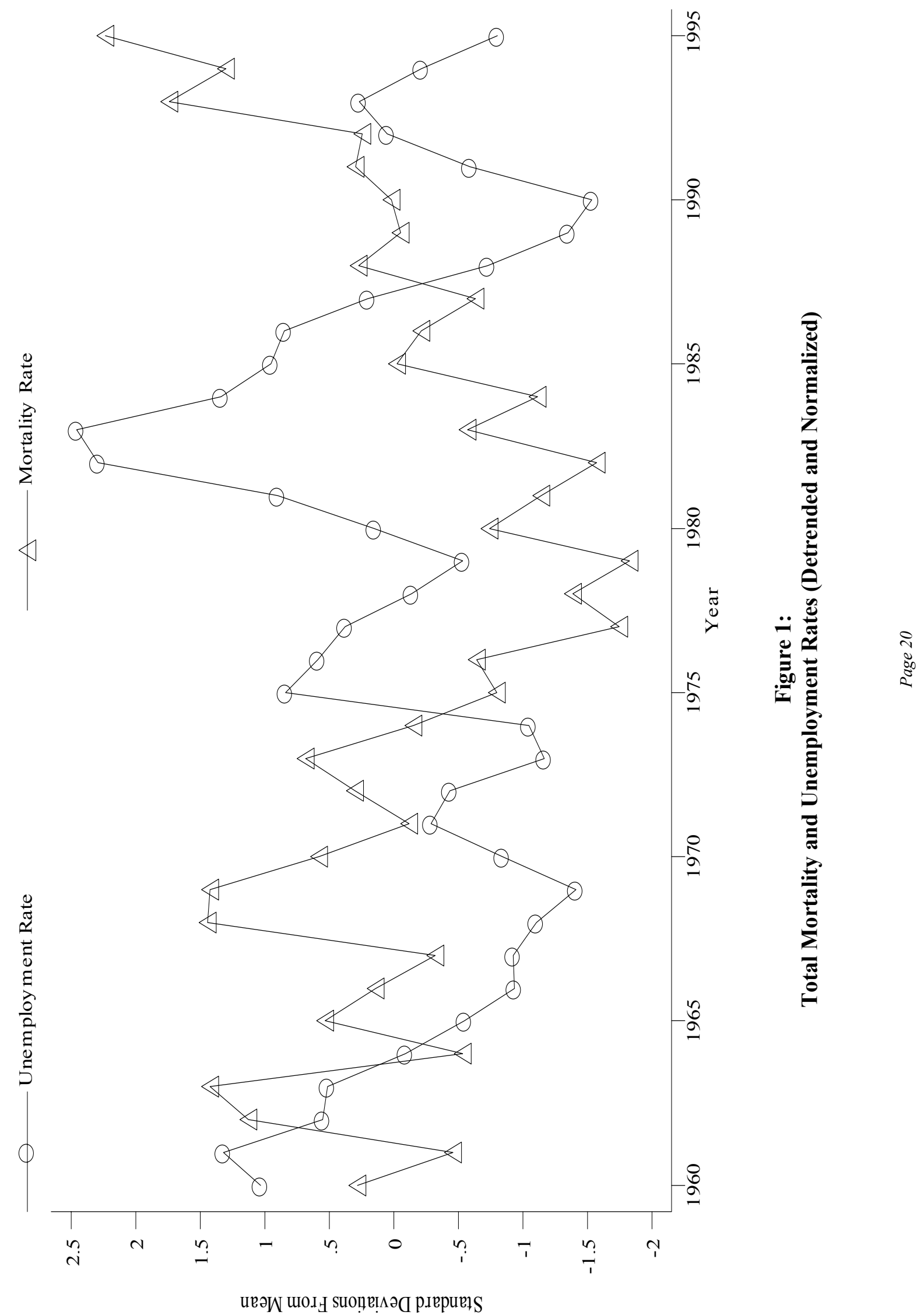




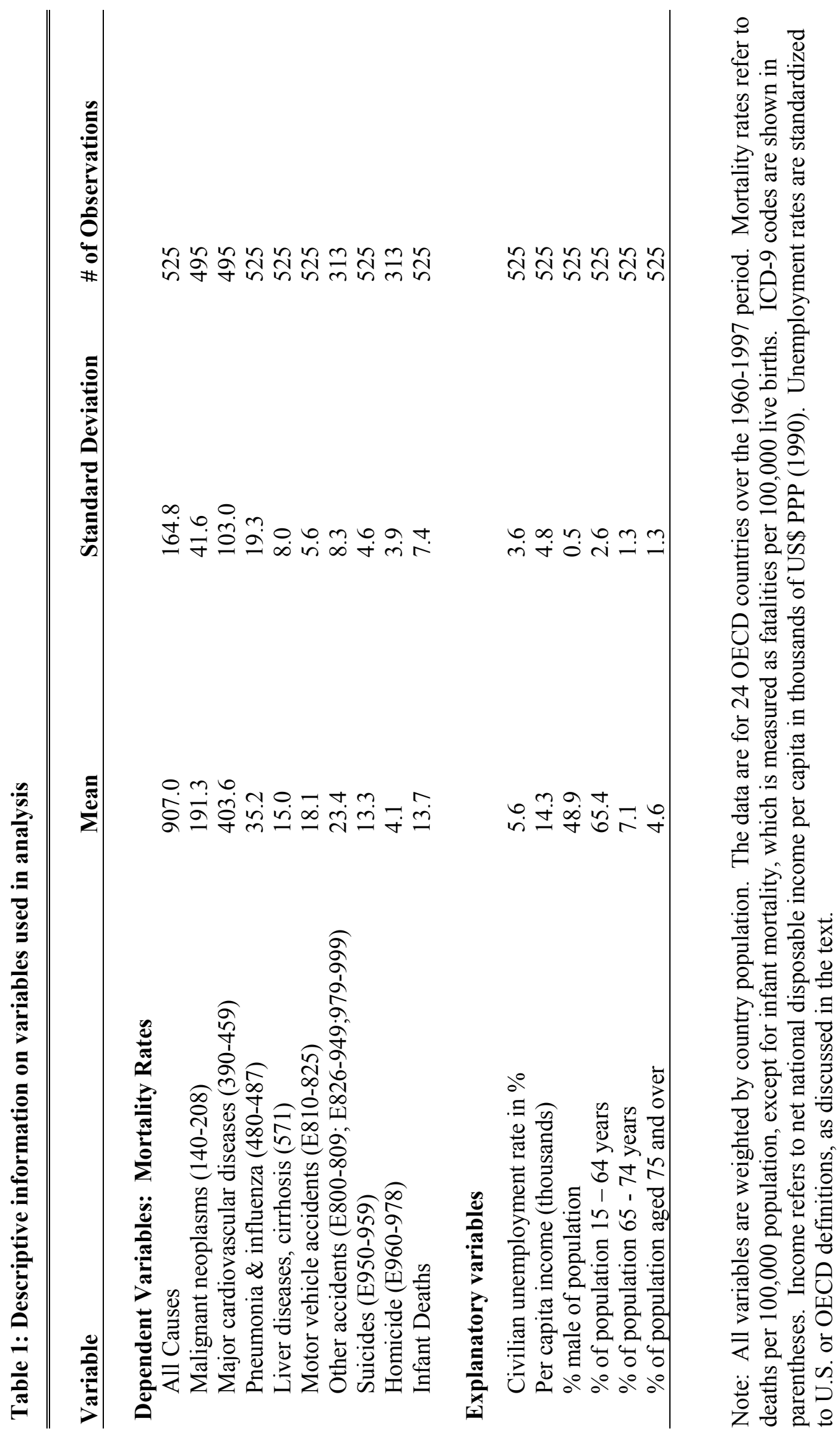




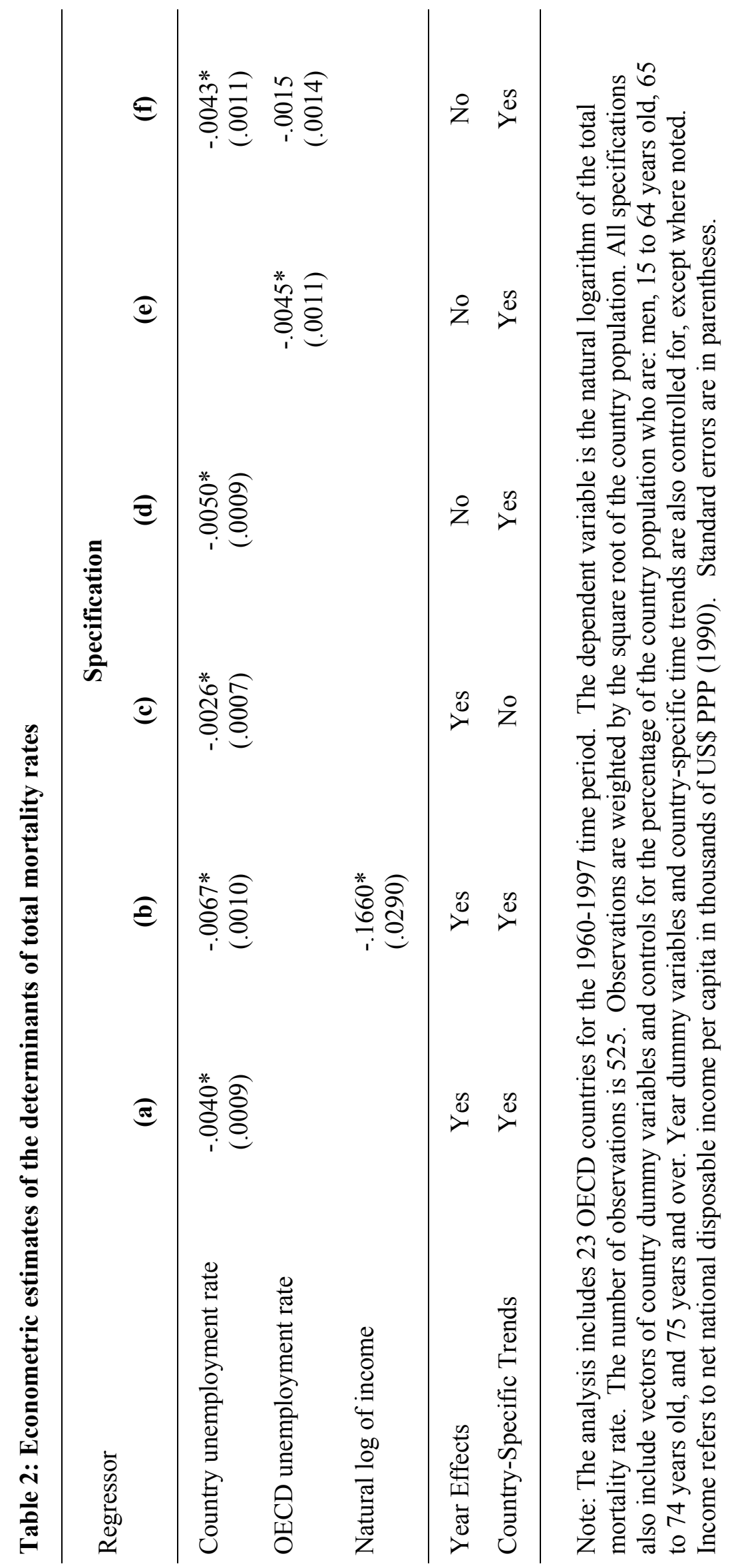




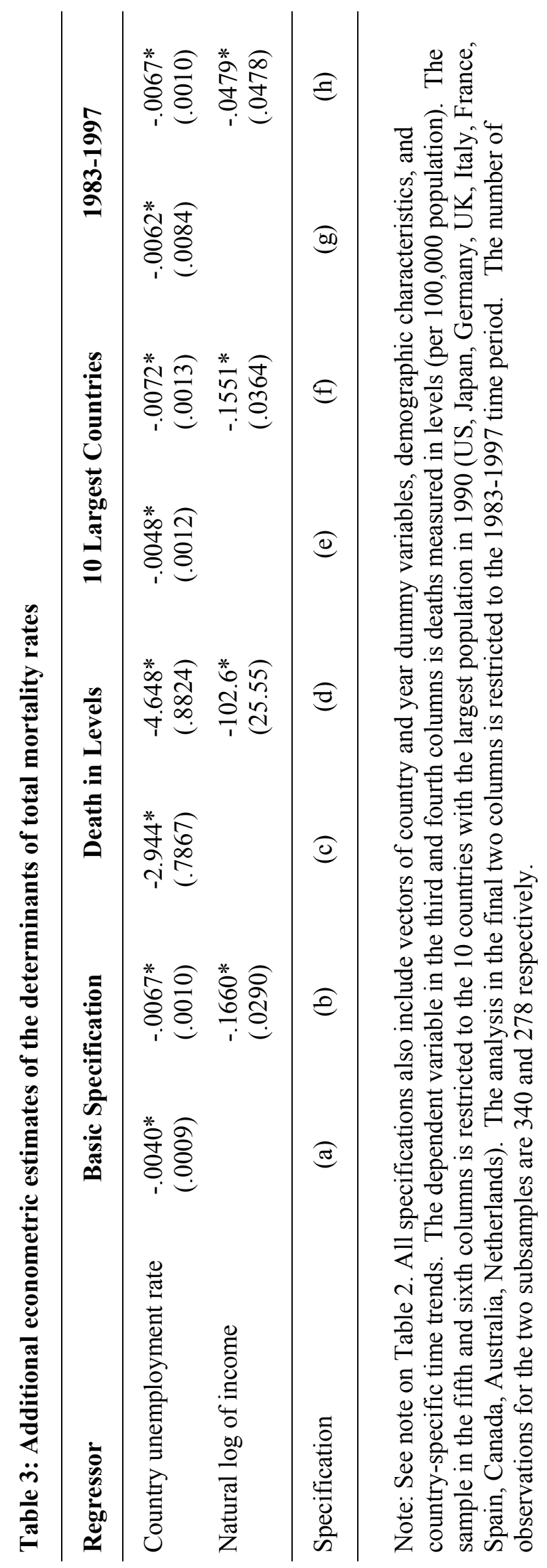




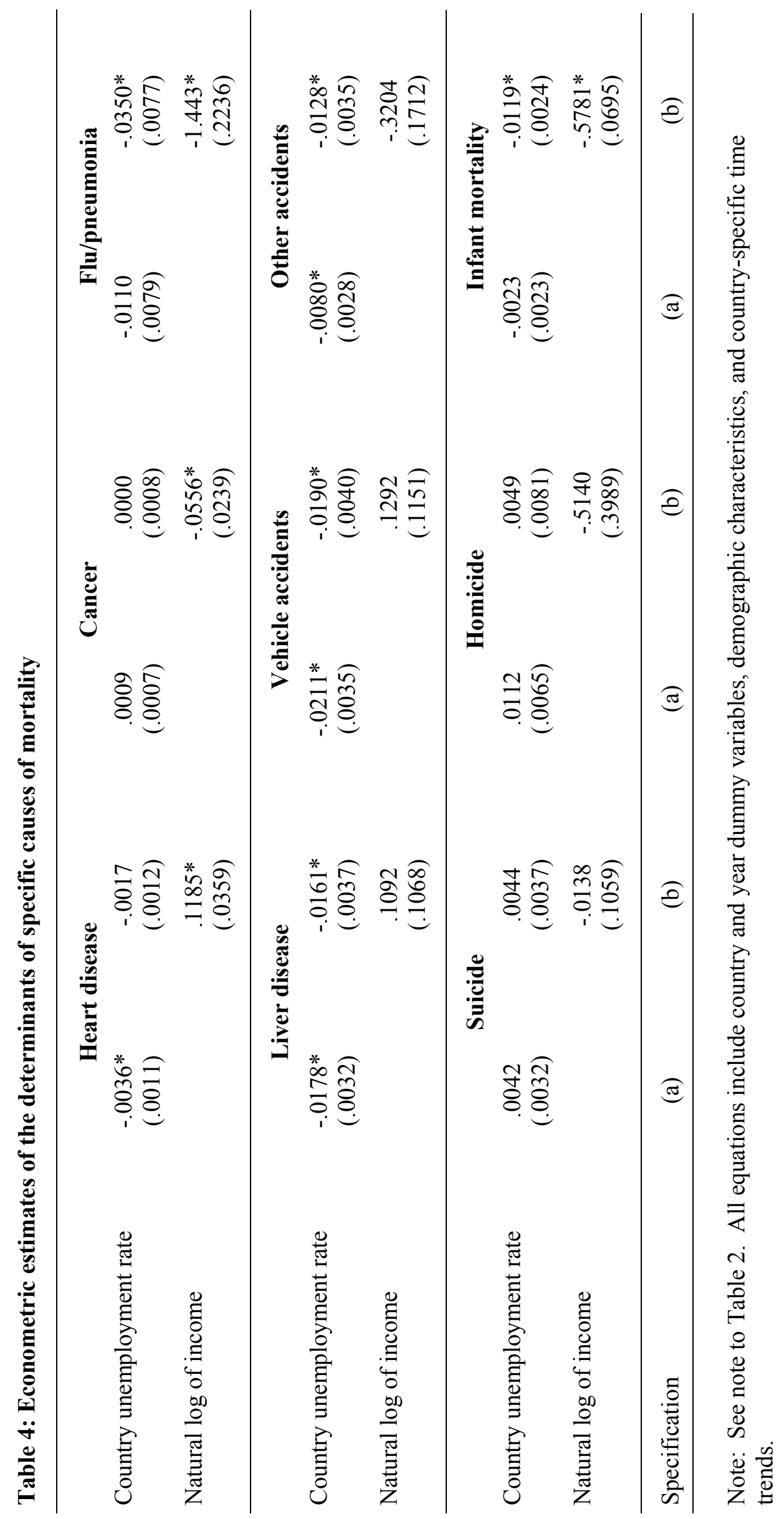

